\title{
Palmitate-Induced MMP-9 Expression in the Human Monocytic Cells is Mediated through the TLR4-MyD88 Dependent Mechanism
}

\author{
Sardar Sindhu Areej Al-Roub Merin Koshy Reeby Thomas Rasheed Ahmad
}

Immunology \& Innovative Cell therapy Unit, Dasman Diabetes Institute, Kuwait

\section{Key Words}

Palmitate • TLR4 • MMP-9

\begin{abstract}
Background/Aims: Obese individuals are known to have increased Matrix metalloproteinase (MMP)-9 plasma levels and MMP-9 is reported to play an important role in obesity-associated adipose tissue inflammation. Since in obesity, the levels of circulatory saturated free fatty acid (FFA) palmitate (palimitic acid) are increased and modulate the expression of inflammatory mediators, the role of palmitate in the regulation of MMP-9 remains unclear. Methods: Human monocytic cell line THP-1 and primary monocytes were stimulated with palmitate and TNF- $\alpha$ (positive control). MMP-9 expression was assessed with real time RT-PCR and ELISA. Signaling pathways were studied by using THP-1-XBlue ${ }^{\mathrm{TM}}$ cells, THP-1-XBlue ${ }^{\mathrm{TM}}$-defMyD cells, anti-TLR4 mAb and TLR4 siRNA. Phosphorylation of NF-kB and c-Jun was analyzed by Western blotting. Results: Here, we provide the evidence that palmitate induces MMP-9 expression at both mRNA (THP-1: $6.8 \pm 1.2$ Fold; $P=0.01$; Primary monocytes: $5.9 \pm 0.7$ Fold; $P=0.0003$ ) and protein (THP1: $1116 \pm 14 \mathrm{pg} / \mathrm{ml} ; P<0.001$; Primary monocytes: $1426 \pm 13.8 ; P=0.0005$ ) levels in human monocytic cells. Palmitate-induced MMP-9 secretion was markedly suppressed by neutralizing anti-TLR-4 antibody $(P<0.05)$. Furthermore, genetic silencing of TLR4 by siRNA also significantly abrogated the palmitate-induced up-regulation of MMP-9. Additionally, MyD88 $\%$ THP-1 cells did not express MMP-9 in response to palmitate treatment. Increased NF-KB/AP-1 activity $(\mathrm{P}<0.05)$ was also observed in palmitate-treated THP-1 cells. Conclusion: Altogether, these results show that palmitate induces TLR4-dependent activation of MMP9 gene expression, which requires the recruitment of MyD88 leading to activation of NFkB/AP-1 transcription factors. Thus, our findings suggest that the palmitate-induced MMP-9 secretion might be an underlying mechanism of its increased levels in obesity and related metabolic inflammation.

A. Al-Roub and M. Koshy contributed equally to this work.

Dr. Rasheed Ahmad, Senior Scientist/ Head Dasman Diabetes Institute, Al-Soor Street, Kuwait, P.O. Box 1180 Dasman, 15462 (Kuwait) of Immunology and Cell Therapy Unit 


\section{Cellular Physiology Cell Physiol Biochem 2016;39:889-900

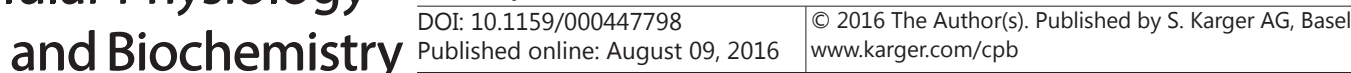 \\ Sindhu et al.: Palmitate Induces MMP-9 in Human Monocytic Cells}

\section{Introduction}

Matrix metalloproteinases (MMPs) comprise a large family of zinc- and calciumdependent extracellular matrix degrading endopeptidases which are categorized into collagenases (MMP-1, -8, -13), gelatinases (MMP-2, -9), stromelysins (MMP-3, -10, -12), matrilysin (MMP-7), and membrane-type matrix metalloproteinases (MT-MMP-1 through -5) based on their structure and specificity [1]. MMPs have pivotal functions in many biological processes including embryogenesis, angiogenesis, inflammation and wound healing, and in normal tissue remodeling [2]. Furthermore, abnormalities in the regulation of MMPs leads to various pathological inflammatory conditions such as heart diseases, arthritis, cancer metastasis and arteriosclerosis. MMP-9 is a gelatinase that has potential enzymatic activity against denatured collagens (gelatin), native type IV and V collagens and elastin. Type IV collagen and laminin are common components of the basement membrane. MMP- 9 can also cleave a variety of non-extracellular matrix (ECM) molecules such as IL-1 $\beta$, substance P, myelin basic protein, and amyloid $\beta$ peptide [3]. MMP-9 is mainly expressed by monocytes/ macrophages and is related with the pathogenesis of inflammatory disorders including cancer metastasis, obesity-induced inflammation, and insulin resistance [4-6]. Levels of MMP-2 and MMP-9 are increased in the inflamed tissue sites. Monocytes/macrophages infiltrate into the areas of chronic inflammation during inflammatory conditions like obesity, arthritis, atherosclerosis, and periodontal disease in which the connective tissue degradation by MMP-9 is considered to trigger the disease pathology [7-10]. MMP-9 induces degradation of the basement membrane and ECM components which facilitates transendothelial migration of monocytes/macrophages [11]. Therefore, MMP-9 inhibition was found to interfere with the macrophage migration to the sites of inflammation [12]. In obesity, MMPs' levels, especially MMP-9, were found to be increased and MMP-9 played a role in the adipose tissue remodeling. [7]. Obesity is characterized by various metabolic abnormalities called metabolic syndrome, such as hyperinsulinemia, hypertriglyceridemia, and increased levels of saturated free fatty acids in the blood which leads to the development of insulin resistance and cardiovascular disease [13-15]. The chronic low-grade inflammation observed in obesity and related metabolic syndrome is marked by increased levels of MMP-9, C-reactive protein, and saturated fatty acids (SFAs) whereas the MMP-9 regulatory stimuli are not fully understood.

In obesity and type- 2 diabetes (T2D), the increased levels of free fatty acids (FFAs) are related with the changes in immune system functioning [16]. Several reports showed proinflammatory effects of SFAs on several cells including monocyte/macrophages, and dendritic cells [17-20]. A possible mechanistic link between FFAs and metabolic diseases are the toll-like receptors (TLRs). TLRs are a family of pattern recognition receptors that activate the innate immune system upon recognition of a wide variety of pathogenassociated molecular patterns, including lipids, lipoproteins, proteins and FFAs [21-23]. Upon stimulation, TLRs engage Toll/Interleukin-1 receptor (TIR) domain-containing adaptor proteins (either myeloid differentiation primary-response protein 88 (MYD88) and MYD88adaptor-like protein (MAL), or TIR domain-containing adaptor protein inducing IFN $\beta$ (TRIF) and TRIF-related adaptor molecule (TRAM). This association leads to the recruitment and activation of IRAK1 and IRAK4, which form a complex with TRAF6 and activate NF-kB /AP-1 [24]. FFAs mediate inflammatory cytokines production in immune cells via TLR-4. Moreover, TLR4 signaling is important for high fat diet-induced insulin resistance, presumably by mediating inflammatory responses within adipose tissue and skeletal muscle [21]. Palmitate, which is the most prevalent dietary SFAs, was reported to induce proinflammatory cytokines including IL-6, TNF- $\alpha$, IL-8, and IL-1 $\beta[19,20,25]$; however, its role in the induction of MMP9 is not yet defined. We hypothesized that palmitate could induce the production of MMP-9 in monocytic cells via an interaction with TLR4. Herein, we show that palmitate can induce MMP-9 in monocytes and this induction involves TLR4/MYD88/NF-KB/AP-1 axis. 


\section{Cellular Physiology Cell Physiol Biochem 2016;39:889-900 \begin{tabular}{l|l} 
and Biochemistry Published online: August 09, 2016 & $\begin{array}{l}\text { (c) } 2016 \text { The Author(s). Published by S. Karger AG, Basel } \\
\text { www.karger.com/cpb }\end{array}$
\end{tabular} \\ Sindhu et al.: Palmitate Induces MMP-9 in Human Monocytic Cells}

\section{Materials and Methods}

\section{Cell Culture}

Human monocytic leukemia cell line THP-1 was purchased from American Type Culture Collection (ATCC) and grown in RPMI-1640 culture medium (Gibco, Life Technologies, Grand Island, USA) supplemented with 10\% fetal bovine serum (Gibco, Life Technologies, Grand Island, NY, USA), 2 mM glutamine (Gibco, Invitrogen, Grand Island, NY, USA), $1 \mathrm{mM}$ sodium pyruvate, $10 \mathrm{mM} \mathrm{HEPES,} 100 \mathrm{ug} / \mathrm{ml}$ Normocin, $50 \mathrm{U} /$ $\mathrm{ml}$ penicillin and $50 \mu \mathrm{g} / \mathrm{ml}$ streptomycin (P/S; (Gibco, Invitrogen, Grand Island, NY, USA), and incubation at $37^{\circ} \mathrm{C}$ (with humidity) in $5 \% \mathrm{CO}_{2}$. THP-1-XBlue cells stably expressing a secreted embryonic alkaline phosphatase (SEAP) reporter inducible by NF- $\kappa \mathrm{B}$ and $\mathrm{AP}-1$ were purchased from InvivoGen (InvivoGen, San Diego, CA, USA). THP-1-XBlue ${ }^{\mathrm{TM}}$-defMyD cells (cells deficient in MyD88 activity or MyD88^- THP-1 cells) were purchased from InvivoGen (San Diego, CA, USA). THP-1-XBlue cells were cultured in complete RPMI medium with the addition of zeocin $(200 \mu \mathrm{g} / \mathrm{ml})$ to select for cells expressing the SEAP-NF- $\mathrm{KB} / \mathrm{AP}-1$ reporter (InvivoGen, San Diego, CA, USA). THP-1-XBlue ${ }^{\mathrm{TM}}$-defMyD cells were cultured in complete RPMI medium with the addition of Zeocin (200 ug/ml) and HygroGold (100 ug/ml) (InvivoGen, San Diego, CA, USA). Prior to stimulation, THP-1 cells were transferred into normal medium and plated in 12-well plates (Costar, Corning Incorporated, Corning, NY, USA) at $1 \times 10^{6}$ cells/well cell density unless indicated otherwise [26].

\section{Peripheral blood mononuclear cells (PBMCs) collection and monocyte isolation}

The human peripheral blood (40 ml) samples were collected from healthy donors in EDTA vacutainer tubes through venipuncture by phlebotomist at the Dasman Diabetes Institute (DDI) and PBMCs were isolated by using Histo-Paque density gradient method as described [27]. Monocytes were isolated from the PBMCs using indirect magnetic colloid labeling method (Monocyte Isolation Kit II; 130-091-153 Miltenyi Biotec, Germany) in which non-monocytic cells including T cells, NK cells, B cells, dendritic cells, and basophils were magnetically labeled with cocktail of biotin-conjugated antibodies against CD3, CD7, CD16, CD19, CD56, CD123, and CD235a (Glycophorin A) surface antigens and anti-biotin MicroBeads. Purified CD14+ monocytes were eluted through the magnetic column and purity was determined by flow cytometry.

\section{Cell stimulation}

Monocytic cells were plated in 6-well plates (Costar, Corning Incorporated, Corning, NY, USA) at $1 \times 10^{6}$ cells/well concentration unless indicated otherwise. Cells were stimulated with palmitate $200 \mathrm{uM}$ (Sigma, San Diego, CA, USA) or TNF $\alpha$ (10 ng/ml; R\&D systems, Minneapolis, USA) or $0.1 \%$ BSA or methyl palmitate 200uM (Sigma, San Diego, CA, USA) for $24 \mathrm{hrs}$ at $37^{\circ} \mathrm{C}$. Cells were harvested for RNA isolation and culture media were collected for measuring MMP-9 secretion.

\section{Small interfering RNA (siRNA) transfections}

THP-1 cells were washed and resuspended in fresh medium without antibiotics and transfected separately with siRNA-TLR4 (30nM; OriGene Technologies, Inc. MD, USA), scramble (control) siRNA (30nM; OriGene Technologies, Inc. MD, USA, USA) and pmaxGFP (0.5 ug; Amaxa Noclecfector Kit V for THP-1, Lonza). All transfection experiments were performed with Amaxa Cell Line Nucleofector Kit V for THP-1 (Lonza, Germany) by using Amaxa Electroporation System (Amaxa Inc, Germany) according to the manufacturer's protocol [28]. Transfection efficiency was analyzed by fluorescence microscopy. After 31 hrs transfection, cells were treated with palmitate $(200 \mathrm{uM})$ for $24 \mathrm{hrs}$. Real time RT-PCR revealed the effective suppression of constitutive TLR4 expression in THP1 cells transfected with specific gene-targeted siRNA.

Measurement of NF- $\kappa B / A P-1$ activity

THP-1-XBlue cells (InvivoGen, San Diego, CA) are THP-1 cells stably transfected with a reporter construct, expressing a secreted embryonic alkaline phosphatase (SEAP) gene under the control of a promoter inducible by the transcription factors NF- $\kappa$ B and AP-1. Upon stimulation, NF- $\kappa$ B and AP-1 are activated and subsequently the secretion of SEAP is stimulated. THP-1 XBlue cells were stimulated with palmitate $(200 \mathrm{uM})$ or TNF- $\alpha\left(10 \mathrm{ng} / \mathrm{ml}\right.$; positive control) for $24 \mathrm{hr}$ at $37^{\circ} \mathrm{C}$. Levels of SEAP were detected in the culture media after 3 hrs incubation of supernatants with Quanti-Blue solution (InvivoGen, San Diego, CA, USA) at $650 \mathrm{~nm}$ wave length by ELISA reader [28]. 


\section{Cellular Physiology Cell Physiol Biochem 2016;39:889-900 \begin{tabular}{cc|c|c|} 
DOI: 10.1159/000447798 & O 2016 The Author(s). Published by S. Karger AG, Basel \\
www.karger.com/cpb
\end{tabular} \\ Sindhu et al.: Palmitate Induces MMP-9 in Human Monocytic Cells}

Real Time RT-PCR

RNeasy Mini Kit (Qiagen, Valencia. CA, USA) was used to extract total RNA. The cDNA was synthesized using $1 \mu \mathrm{g}$ of total RNA using high capacity cDNA reverse transcription kit (Applied Biosystems, Foster city, CA, USA). 50ng cDNA was used in each real time polymerase chain reaction (PCR) reaction. For real time PCR, complementary DNA was amplified with Inventoried TaqMan Gene Expression Assay products (MMP-9: Hs00234579_m1; GAPDH: Hs03929097_g1; TLR-4: Hs00152939_ml) containing two gene-specific primers and one TaqMan MGB probe (6-FAM dye-labeled) using a TaqMan ${ }^{\circledR}$ Gene Expression Master Mix (Applied Biosystems, Foster city, CA, USA) in a 7500 Fast Real-Time PCR System (Applied Biosystems, Foster City, CA, USA). The mRNA levels were normalized against GAPDH mRNA and the amounts of MMP-9 mRNA relative to control were calculated with $\Delta \Delta$ Ct-method [20]. Relative mRNA expression was expressed as fold expression over average of control gene expression. The expression level in control treatment was assumed to be 1 . Values are presented as mean \pm SEM. Results were analyzed using unpaired student t test; $P<0.05$ was considered significant.

\section{Secreted MMP-9 quantification}

MMP-9 secreted protein in supernatants of monocytic cells stimulated with palmitate or TNF- $\alpha$ was quantified using sandwich ELISA following the manufacturer's instructions (R\&D systems, Minneapolis, USA).

\section{Immunocytofluorescence}

THP-1 cells $\left(10^{6} / \mathrm{mL}\right)$ were washed and coated on slides (FisherbrandTM Superfrost TM Plus Microscope Catalogue No 12-550-15) using cyto-spin technique at 500rpm for 3mins. The slides were then fixed in $4 \%$ formaldehyde and washed three times in cold PBS Cells were then permeabilized using in $0.1 \%$ Triton X-100, followed by three washes in cold PBS. The cells were blocked in $1 \%$ bovine serum albumin for $1 \mathrm{hr}$. The slides were incubated overnight at room temperature with primary antibody of rabbit polyclonal anti MMP-9 antibody (abcam ${ }^{\circledR}$ ab137867) in 1:50 dilution. The cells were then washed in PBS containing $0.05 \%$ Tween three times and again incubated with the secondary antibody conjugated with Alexa Fluor $594\left(\right.$ abcam $^{\circledR}$ ab150088) 1:200 dilution for 1hr. After washing the slide several times in PBS, the cells were counterstained and mounted with coverslip using mountant containing DAPI (Vectashield, Vectorlab, H1500).

The confocal images of the THP1 cells were collected on inverted Zeiss LSM710 AxioObsever microscope (Carl Zeiss, Gottingen, Germany) using Plan-Apochromat 63X/1.40 oil DIC M27 objective lens. Excitation was via a $543 \mathrm{~nm}$ HeNe solid-state laser and the $405 \mathrm{~nm}$ line of an argon ion laser. After laser excitation of the samples, optimized emission detection bandwidths were configured by Zeiss Zen 2010 control software subsequently the confocal images were captured.

\section{Western blotting}

Cellular lysates were prepared and protein was resolved on SDS-12\% SDS-PAGE as described previously (Ahmad r, 2014, Ahmad $r$ 2015). The blots were probed with rabbit anti-human antibodies against p-cJun, total c-Jun, p-NF-kB and total NF-kB in 1:1000 dilution at $4{ }^{\circ} \mathrm{C}$ overnight. All the primary antibodies were purchased from Cell Signalling (Cell Signalling Technology, Inc). The blots were then washed three times with TBS and incubated for $2 \mathrm{~h}$ with HRP-conjugated secondary antibody (Promega, Madison, WI, USA). Immunoreactive bands were developed using an Amersham ECL Plus Western Blotting Detection System (GE Health Care, Buckinghamshire, UK) and visualized by Molecular Imager ${ }^{\circledR}$ VersaDoc $^{\mathrm{TM}}$ MP Imaging Systems (Bio-Rad Laboratories, Hercules, CA, USA).

\section{Statistical analysis}

Statistical analysis was performed using GraphPad Prism software (La Jolla, CA, USA). Data are shown as mean \pm standard deviation values, unless otherwise indicated. Unpaired Student t-test was used to compare means between groups. For all analyses, $P$ value $<0.05$ was considered significant. 


\section{Cellular Physiology Cell Physiol Biochem 2016;39:889-900

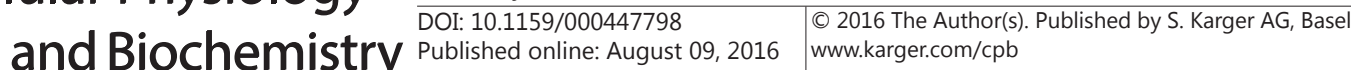 \\ Sindhu et al.: Palmitate Induces MMP-9 in Human Monocytic Cells}

\section{Results}

Palmitate induces MMP-9 expression in the human monocytic THP-1 cells as well as primary monocytes

In obesity and T2D, increased levels of both palmitate and MMP-9 have been reported and MMP-9 plays a key role in immune cell infiltration into the adipose tissue and exacerbate inflammation $[5,6]$. We asked if palmitate could induce the induction of MMP-9 in monocytic cells. To this end, our data show that MMP-9 mRNA expression levels were significantly higher (THP-1: $6.8 \pm 1.2$ Fold; $P=0.01$; Primary monocytes: $5.9 \pm 0.7$ Fold; $P=0.0003$ ) in palmitatetreated monocytic cells than controls (cells treated with vehicle only) (Fig. 1A \& C). As expected and in agreement with MMP-9 gene expression, levels of MMP-9 secretory protein were also significantly higher (THP-1: $1116 \pm 14 \mathrm{pg} / \mathrm{ml} ; P=0.001$; Primary monocytes: 1426 \pm 13 .8; $P=0.0005$ ) in supernatants from palmitate-treated monocytic cells as compared with vehicle-treated control cells (THP-1: $326 \pm 43 \mathrm{pg} / \mathrm{ml}$; Primary monocytes: $251 \pm 36$ )

Fig. 1. Effect of palmitate on MMP9 expression in human monocytic cells. THP-1 cells were treated with palmitate $(200 \mathrm{uM}), \mathrm{TNF}-\alpha(10$ $\mathrm{ng} / \mathrm{ml}$; positive control) and $0.1 \%$ BSA (vehicle) for $24 \mathrm{hrs}$. Cells and culture media were collected. Total RNA was isolated and MMP-9 mRNA was quantified by real time PCR. Relative mRNA expression was expressed as fold expression over average of gene expression in BSA treated cells (A). Secreted MMP-9 protein in culture media was determined by ELISA (B). Monocytes were isolated from PBMCs of healthy volunteers. Monocytes were treated with Palmitate, TNF- $\alpha$ and BSA for 24 hrs. Cells and culture media were collected. MMP-9 mRNA was determined by real time PCR (C). Secreted MMP9 in culture media was determined by ELISA (D). THP-1 cells were immune-stained with rabbit polyclonal anti MMP-9 antibody (abcam ${ }^{\circledR}$ ab137867) followed by secondary antibody conjugated with Alexa Fluor 594 (abcam $\AA$ ab150088) (red) for MMP-9 expression (arrows) under confocal laser scanning microscope. Nuclei were stained with DAPI (blue) The confocal images of the THP1 cells were collected on inverted Zeiss LSM710 AxioObsever microscope

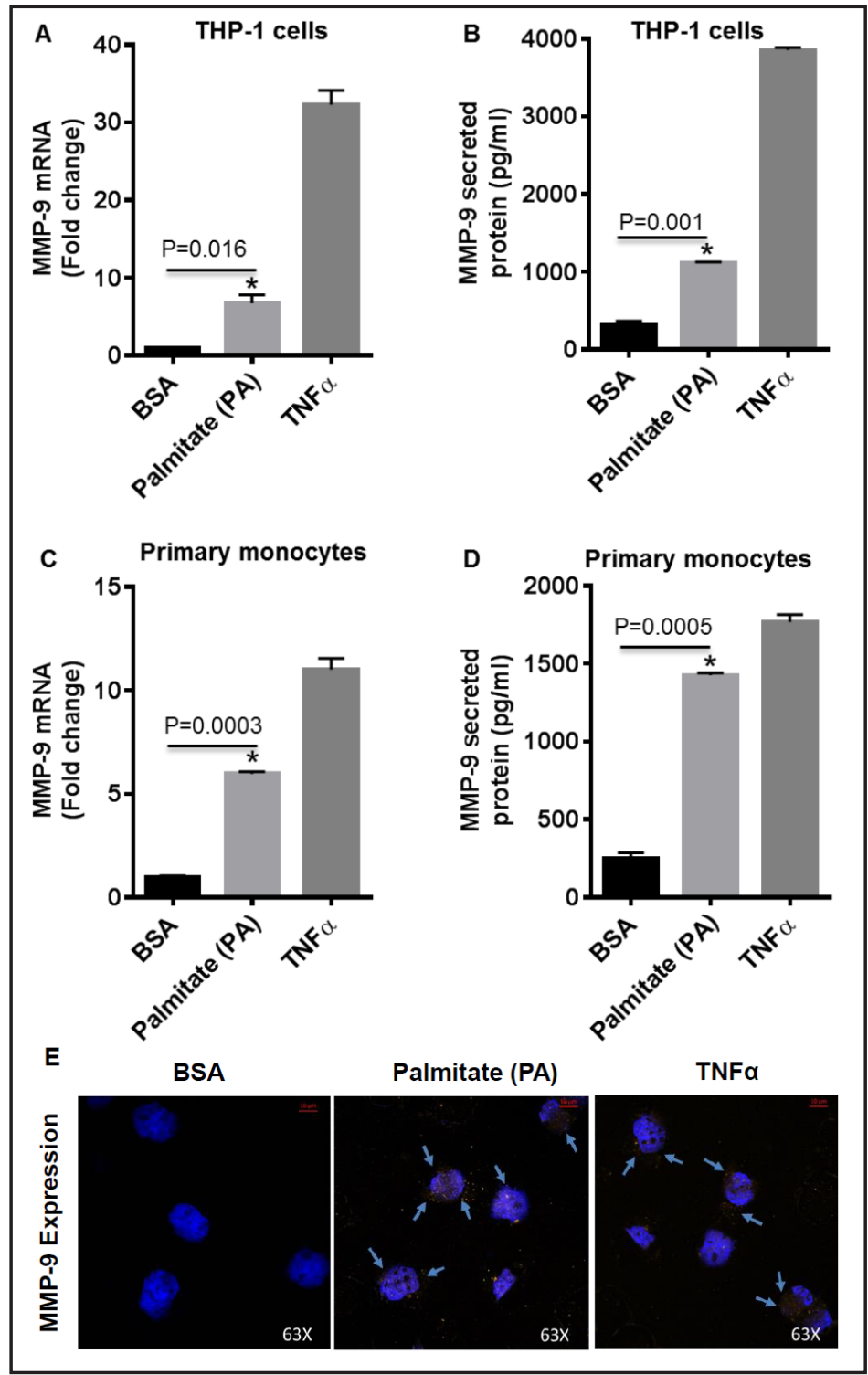

(Carl Zeiss, Gottingen, Germany) using Plan-Apochromat 63X/1.40 oil DIC M27 objective lens (E). Data are shown as mean \pm SD of three independent experiments on different donors from a representative experiment of three. 


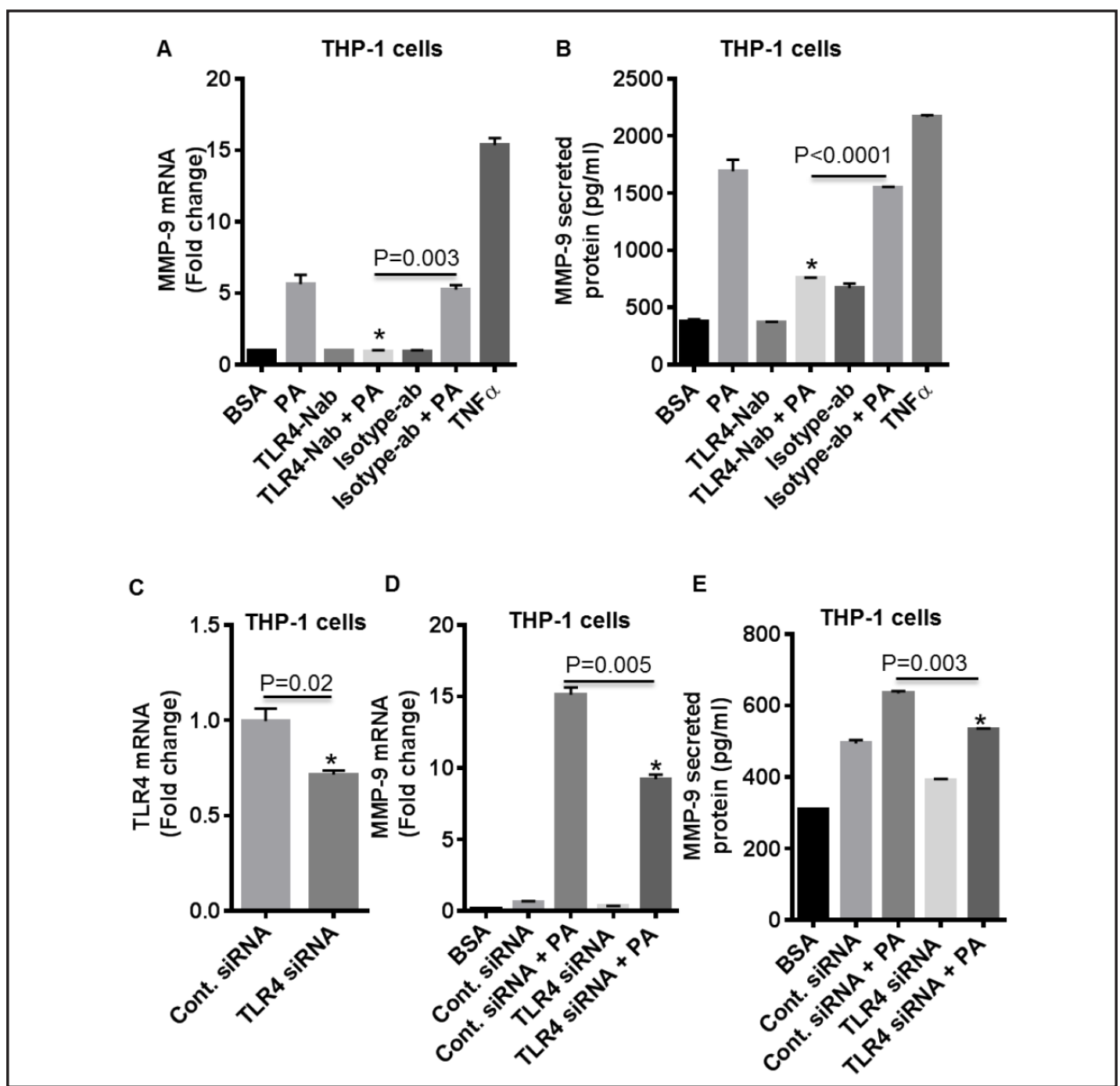

Fig. 2. Inhibition of TLR4 down-regulates the palmitate induced MMP-9. THP-1 cells were treated with 2 $\mu \mathrm{g} / \mathrm{mL}$ of neutralizing TLR4 mAb or isotype-matched control (IgA) for 40 minutes. Antibody-treated cells were stimulated with palmitate or BSA and incubated for $24 \mathrm{hrs}$. Cells and culture media were collected. Total RNA was isolated from cells and MMP-9 mRNA was quantified by real time PCR (A) and secreted MMP-9 protein was determined in the culture media by ELISA (B). THP-1 cells were transfected with either control siRNA (30nM) or siRNA (30 nM) against TLR4 and incubated $36 \mathrm{hrs}$. Real time PCR was done to measure TLR4 expression (C). TLR4 deficient cells were treated with palmitate and BSA for 24 hours. Real time PCR was done to measure MMP-9 mRNA expression (D) and ELISA was done to measure secreted MMP-9 protein (E).

(Fig. 1B and D). These data show that palmitate was able to induce MMP-9 expression at both gene and protein levels in the human cells of monocytic lineage. Confocal microscopy of monocytic THP- 1 cells also showed that there was an increase in the expression of MMP-9 in palmitate treated cells (E).

Palmitate induction of MMP-9 in monocytic cells involves the TLR4 innate immune receptor

Saturated fatty acids are known to mediate inflammatory cytokine production through the interaction with the innate immune TLR4 receptor in monocytes/macrophages [22]. We, therefore, asked if palmitate-induced MMP-9 expression in monocytic cells was dependent on cognate signaling via the surface TLR4 receptor on these cells. To address this issue, we used TLR4 receptor blocking antibody and isotype control antibody to label cells before 
Fig. 3. MyD88 deficiency reduced the palmitate induced production of MMP-9. THP-1 XBlue defMyD cells (cells deficient in MyD88 activity) were treated with palmitate $(200 \mu \mathrm{m})$ or $0.1 \%$ BSA (Vehicle) or TNF- $\alpha$ (10 ng/ml; MyD88 independent stimulus). Cells and culture media were collected after 24 hrs. MMP-9 gene expression was determined by real time PCR (A) and secreted MMP-9 protein was determined in culture media by ELISA (B).

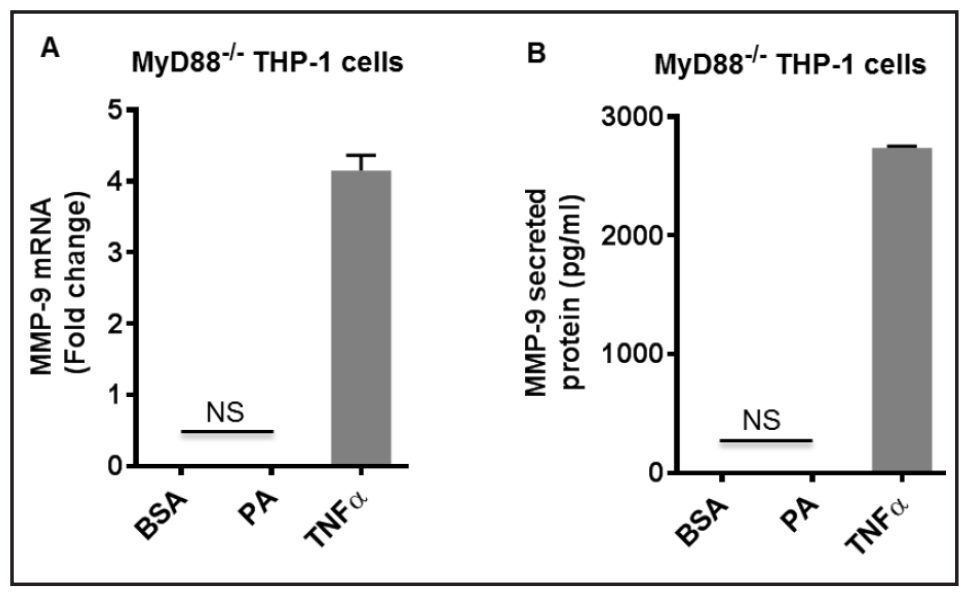

Fig. 4. Palmitate metabolism is not significantly required for the induction of MMP-9. THP-1 cells were treated with methylpalmitate $(200 \mu \mathrm{m}$; non metabolizable analog of palmitate) or palmitate or BSA for 24 hrs. Cells and culture media were collected. MMP-9 gene expression was determined by real time PCR (A) and secreted MMP-9 protein was determined in culture media by ELISA (B).

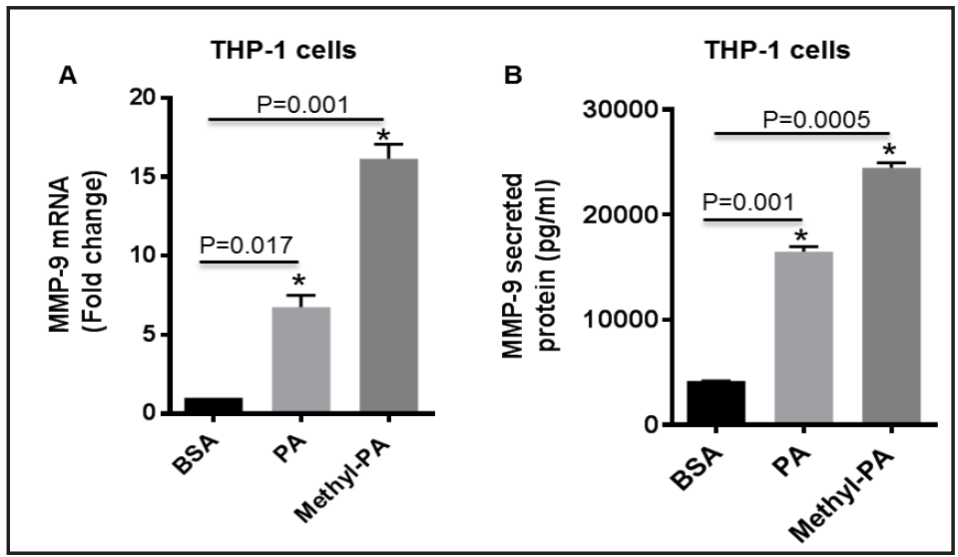

palmitate stimulation. In this regard, our data show that anti-TLR4 antibody pre-treatment significantly inhibited the palmitate-induced MMP-9 gene (Fig. 2A; $P=0.003$ ) and protein $(762 \pm 20 \mathrm{pg} / \mathrm{ml} P<0.0001)$ (Fig. 2B) expression in THP-1 monocytic cells while there was no MMP-9 suppression observed in the cells labeled with isotype control antibody $(1547 \pm 10 \mathrm{pg} / \mathrm{ml})$. Furthermore, TLR4 suppression in THP-1 cells was also achieved by transfection with TLR4-specific siRNA (Fig. 2C) and we found that palmitate-induced MMP9 gene/protein expression was significantly suppressed $(P<0.05)$ in TLR4 specific siRNAtransfected cells as compared with scramble siRNA-transfected control cells (Fig. 2D and E). These data suggest that palmitate induces MMP-9 gene/protein expression by signaling through the TLR4 receptor.

\section{Palmitate-induced MMP-9 expression is MyD88-dependent}

MyD88 is a key adaptor protein involved in TLR-mediated signaling and triggering of downstream cascades that regulate the expression of inflammatory mediators $[27,28]$. We asked whether the palmitate-induced MMP-9 expression in THP-1 monocytic cells was MyD88-dependent or -independent and to address this, we treated THP-1-XBlue ${ }^{\mathrm{TM}}$-defMyD cells (THP-1 cells deficient in MyD88 (MyD88\% THP-1 cells) with palmitate or TNF- $\alpha$ (positive control). To this end, the data show that palmitate-induced MMP-9 expression was significantly reduced in MyD88\%- THP-1 cells at both mRNA and protein levels (Fig. 3A and B; $\mathrm{P}<0.05$ ) whereas the TNF- $\alpha$-induced MMP-9 expression was not affected in MyD88-/- cells as it was independent of MyD88 pathway (Fig. 3A and B). These data further substantiate the TLR4-mediated expression of MMP-9 in monocytic cells.

Palmitate induces MMP-9 expression via surface receptor-mediated signaling mechanism

Since palmitate can induce cellular activation through the receptor-mediated signaling as well as alternative pathway involving its uptake and breakdown into metabolites [16, 29], 
Fig. 5. Palmitate activates NF-kB and AP-1 transcription factors. THP1 cells were treated with palmitate for different time points and cell lysates were prepared as described in methods. Samples were run on denaturing gels. Phosphorylated NF-kB and c-Jun are depicted in the upper panels and total respective proteins are shown in the lower panels (A). THP-1-XBlue cells (THP-1 cells stably expressing a secreted embryonic alkaline phosphatase (SEAP) reporter inducible by $N F-\kappa B$ and AP-1) were treated with palmitate or BSA or TNF- $\alpha$ for $24 \mathrm{hrs}$. Culture media were collected. Cell culture media were assayed for SEAP reporter activity (degree of NF- $\kappa \mathrm{B}$ / AP-1 activation) along with MMP-9 production (B and C). Similarly THP1-XBlue ${ }^{\mathrm{TM}}$-defMyD cells (Cells deficient in MyD88 activity) were treated with palmitate (200 um), TNF- $\alpha$ (10 ng/ml) and 0.1\% BSA for $24 \mathrm{hrs}$. SEAP reporter activity (degree of NF- $\kappa B$ /AP-1 activation) along with the secreted MMP-9 protein was determined in the cell culture media (D and E). The results obtained from three independent experiments are shown. The data are presented as mean \pm SD.

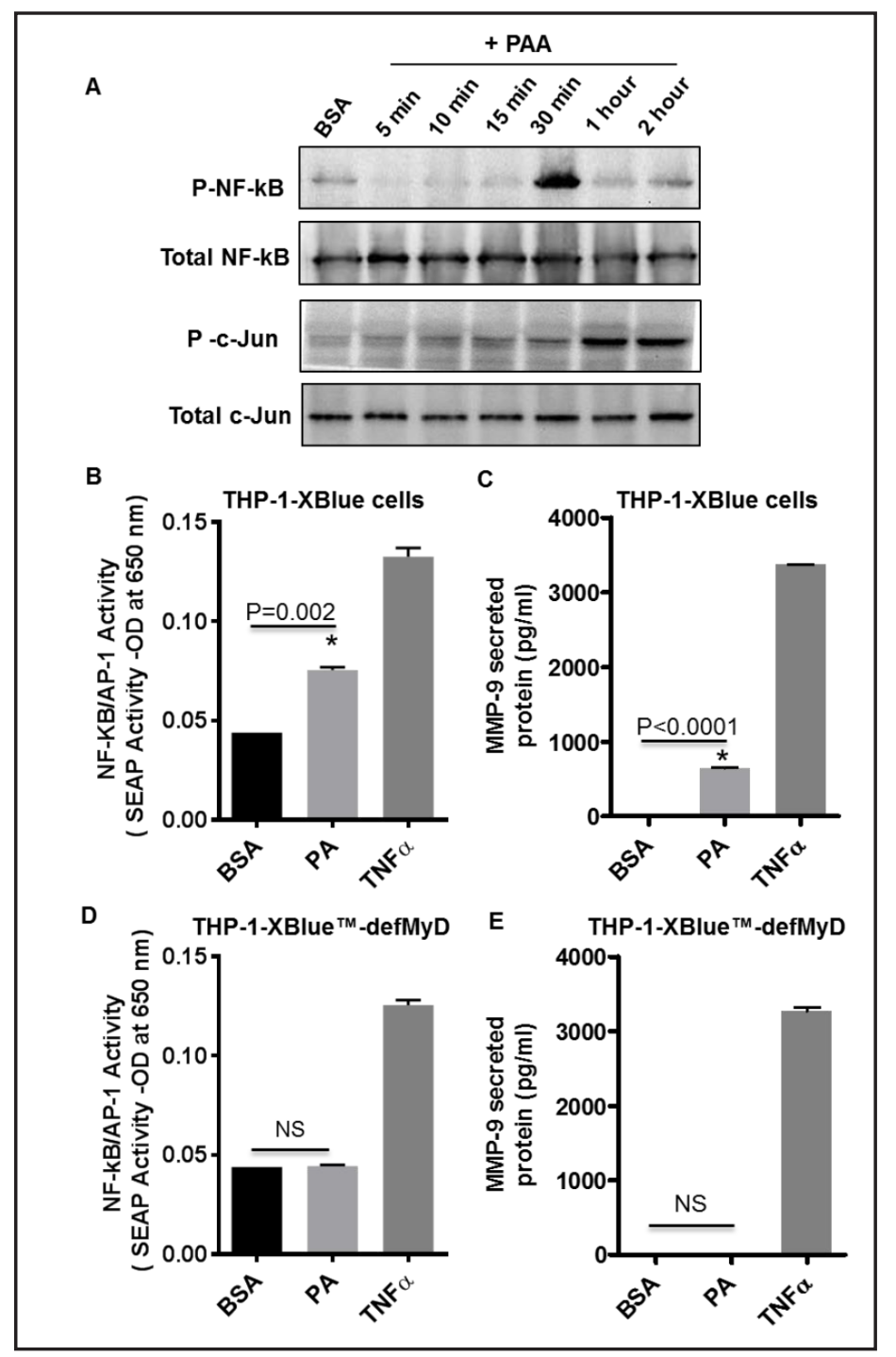

we asked if MMP-9 induction in monocytic cells involved one or both of these mechanisms. To investigate this, a non-metabolizable palmitic acid (palmitate) analog known as methyl palmitate was used to stimulate monocytic cells. To this effect, our data show that MMP9 expression at both mRNA (16.15 \pm 1.92 Fold; $P=0.001)$ and protein $(2445 \pm 65 \mathrm{pg} / \mathrm{ml}$; $P=0.0005)$ levels was significantly higher in the cells treated with palmitate analog as compared with controls $(4170 \pm 17 \mathrm{pg} / \mathrm{ml}$ ) (Fig. 4A and B). This finding suggests that MMP9 was induced in monocytic cells through the surface-mediated signaling mechanism.

\section{Palmitate-induced MMP-9 expression is regulated via NF-kB and AP-1}

Both the human and murine MMP-9 gene promoter contains NF- $\mathrm{BB} / \mathrm{AP}-1$ transcription factor binding sites and activation of NF- $\mathrm{KB} / \mathrm{AP}-1$ led to the induction of MMP-9 in monocytic cells by different stimuli $[28,30]$. We next asked if the MMP-9 induction in THP-1 monocytic cells was associated with the increased NF- $\mathrm{KB} / \mathrm{AP} 1$ activity in these cells. To this end, our data show that THP-1 cells stimulation with palmitate increased NF-kB and c-Jun (a major component of AP-1 transcription) phosphorylation (Fig. 5A). We further confirmed the involvement of NF- $\mathrm{KB} / \mathrm{AP} 1$ in palmitate-induced MMP-9 production by using culture media obtained from palmitate-treated THP-1 cells that were expressing a reporter driven by NF- $\kappa B$ and AP-1 response elements to analyze NF- $\kappa B / A P-1$ activity. As expected, NF- $\kappa B$ / AP-1 activity was strongly induced in palmitate-treated cells $(\mathrm{P}=0.002)(\mathrm{Fig} .5 \mathrm{~B})$ and this 


\section{Cellular Physiology Cell Physiol Biochem 2016;39:889-900

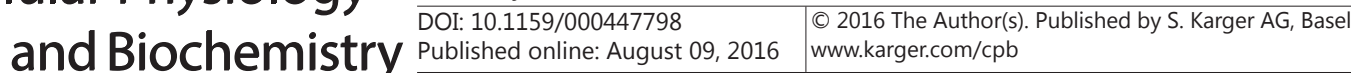 \\ Sindhu et al.: Palmitate Induces MMP-9 in Human Monocytic Cells}

NF- $\kappa \mathrm{B} / \mathrm{AP}-1$ induction correlated with MMP-9 secretion (Fig. 5C). In addition, the lack of MyD88 also led to significantly reduced NF- $\mathrm{KB} / \mathrm{AP}-1$ activity and protein following palmitate treatment (Fig. 5D and E). These data suggest that palmitate-induced upregulation of MMP9 gene expression in monocytic cells involves activation of the NF- $\kappa \mathrm{B} / \mathrm{AP}-1$ transcription factors via the MyD88-dependent signaling mechanism.

\section{Discussion}

The SFA palmitate and MMP-9 are found to be elevated in the plasma and tissues of obese and diabetic individuals $[15,16]$ which is thought to contribute to the obesityassociated pathogenesis whereas the molecular mechanisms underlying such associations largely remain unclear. Palmitate induces the expression of IL-1 $\beta$, TNF- $\alpha$, and IL-8 in human monocytic cells while the palmitate-mediated MMP-9 expression in human monocytic cells has not been studied. We herein show for the first time, to our knowledge, that palmitate which is one of the most abundant FFAs in the human circulation induces expression of MMP-9 in monocytic cells. These data add palmitate as a novel potent inducer of MMP-9 in the human monocytic cells to the repertoire of known MMP-9 stimuli including IL-1 $\beta$, TNF- $\alpha$, MCP-1, LPS, Insulin, FSL-1 and HKLM [26, 28, 31-35].

Over the past decade, substantial progress has been made in understanding the molecular mechanisms of the induction of inflammatory responses to palmitate stimulation of the innate immune receptor TLR4 $[22,36]$ and its role of immunometabolic interactions in promoting insulin resistance and atherosclerosis [37]. TLR4 signaling pathway was activated in macrophages by SFAs. Of note, palmitate-induced TLR4 signaling in monocytes/ macrophages was shown to play a role in the production of inflammatory mediators [38]. Notably, immune cells of monocytic lineage are known to highly express the TLR4 receptor and we found that these cells expressed high levels of MMP-9 following stimulation with palmitate, therefore, we sought to assess the role of TLR4-mediated signaling in the production of MMP-9 by palmitate-treated monocytic cells. In this regard, we found that palmitate-induced MMP-9 production by monocytic cells was markedly reduced after pretreatment of cells with anti-TLR4 neutralizing antibody. As expected, MMP-9 production was also significantly suppressed in monocytic cells that were transfected with TLR4-specific siRNA for genetic suppression of TLR4-mediated signaling. These data show that palmitateinduced TLR4 signaling was involved in the upregulation of MMP-9 expression in monocytic cells. Palmitate up-regulated the expression of IL- 6 and cyclooxygenase 2 in chondrocytes and fibroblast-like synoviocytes through Toll-like receptor 4 (TLR-4) signaling [39]. Moreover, some studies have demonstrated that SFAs induce IL-6 via TLR2 or TLR4 receptors in myocytes, macrophages, and adipocytes [22, 40]. However, few studies described that fatty acid metabolism was required for the induction of IL- 6 in endothelial and monocytic cells $[25,29]$. Thus, it shows that SFAs are inducers of different cytokines in various cell types via different molecular mechanisms. Since palmitate is also known to activate cells by its uptake and intracellular metabolites [29], we further investigated whether or not MMP-9 expression in monocytic cells was dependent on palmitate uptake and metabolism. To this end, we used a non-metabolizable, TLR4 agonistic palmitic acid analog called methyl palmitate (methyl PA) and we found that analog induced strong MMP-9 expression in monocytic cells which implies that cognate receptor-ligand surface interaction was necessary and sufficient to induce MMP-9 expression in monocytic cells. We, therefore, conclude that MMP-9 induction in monocytic cells requires activation of TLR4 signaling by palmitate which does not require additional activation by palmitate uptake and metabolism. Studies showed that methyl PA did not induce IL-6 and TNF-alpha in monocytes [29] whereas, we found that it induces MMP-9 and this discrepancy may be explained as follows. PA induces MMP-9 via two plausible mechanisms: (1) PA as ligand interacts with TLR4 and induces MMP-9 expression; (2) PA is also uptaken and metabolized which may induce the biologicallyrelevant concentration of TNF- $\alpha$ which can also contribute to a certain level in inducing 


\section{Cellular Physiology Cell Physiol Biochem 2016;39:889-900

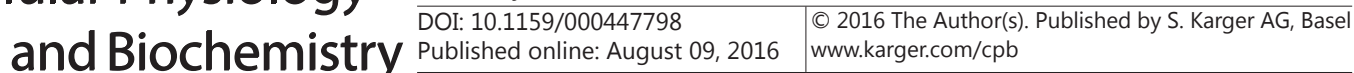 \\ Sindhu et al.: Palmitate Induces MMP-9 in Human Monocytic Cells}

MMP-9 expression in THP-1 cells. But in case of methyl PA, the only signal involved in MMP-9 expression is the surface interaction between methyl PA and TLR4 whereas, in this case, no TNF- $\alpha$-mediated MMP-9 induction is involved since methyl PA cannot be metabolized i.e a condition which is required for TNF- $\alpha$ expression, as supported by the previous study [29]. Given the afore-mentioned, methyl PA, as a non-metabolizable ligand to TLR4, appears to induce significantly higher expression of MMP-9, perhaps due to a sustained TLR-4 mediated signaling stimulus. Ligand recognition by TLRs triggers the activation of signaling cascade which results in the recruitment of adaptor proteins to the TIR domain. MyD-88 is one of the most common adaptor protein for all TLRs except TLR3 and it leads to downstream signaling

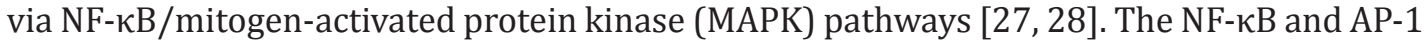
transcription factors are critical regulator of the expression of MMP9 that contribute to the immune changes [26]. By knocking down MyD88 adaptor protein, we show that palmitateinduced MMP-9 expression in monocytic cells was MyD88-dependent. Further, SFAs modulate the activation of TLR4 and its downstream signaling pathways involving MyD88/ IRAK/TRAF6 [41]. Our data further show that palmitate induces NF-kB/AP-1 activation in monocytic cells. Similarly, palmitic acid induced significantly elevated levels of IL-8 in hepatocytes, detectable at both mRNA and protein levels through the mechanisms involving activation of NF-kB and JNK/AP-1 [42]. Moreover, SFAs modulate the activation of TLR4 and its downstream signaling pathways involving MyD88/IRAK/TRAF6 [17]. In agreement with these observations, MMP-9 expression in THP-1 cells by different stimuli was found to be MAPK/NF- $\mathrm{KB} / \mathrm{AP}-1$ dependent $[26,28]$.

In summary, we herein show for the first time that palmitate induces MMP-9 expression in human monocytic cells and also that MMP-9 gene induction involves signaling through the TLR4/MyD88 and NF- $\mathrm{kB} / \mathrm{AP}-1$ trans-activation. A clear understanding of the molecular mechanisms regulating MMP-9 gene expression in monocytic cells may help identify novel approaches, such as blocking of key molecules activated by MMP-9 expression in response to SFAs, to down modulate chronic inflammation associated with metabolic diseases such as obesity and type-2 diabetes.

\section{Abbreviations}

AP-1 (Activating protein-1); ATCC (American Type Culture Collection); ECM (Extracellular matrix); ELISA (Enzyme-linked immunosorbent assay); FAA (Free fatty acid); FSL-1 (Fibroblast-stimulating lipopeptide-1); GAPDH (Glyceraldehyde-3-phosphate dehydrogenase); LPS (Lipopolysaccharide); MAPK (Mitogen-activated protein kinase); MMP9 (Matrix metalloproteinase-9); MyD88 (Myeloid differentiation factor 88); NF-кB (Nuclear factor-kappaB); PA (Palmitate (palimitic acid)); PBMC (Peripheral blood mononuclear cells); PCR (Polymerase chain reaction); SFA (Saturated fatty acid); SEAP (Secreted embryonic alkaline phosphatase); THP-1 (A human monocytic cell line); TIR (Interleukin (IL)-1 receptor called toll-IL1-R); TLRs (Toll-like receptors); TNF- $\alpha$ (Tumor necrosis factor-alpha).

\section{Acknowledgements}

This study was financially supported by Kuwait Foundation for the Advancement of Sciences (KFAS).

\section{Disclosure Statement}

The authors declare that they have no competing interests. 


\section{Cellular Physiology Cell Physiol Biochem 2016;39:889-900

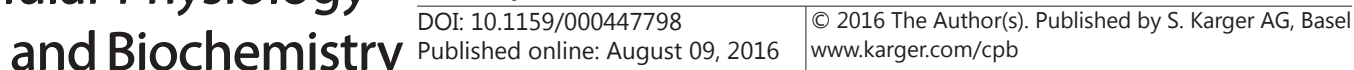 \\ Sindhu et al.: Palmitate Induces MMP-9 in Human Monocytic Cells}

\section{References}

1 Webster NL, Crowe SM: Matrix metalloproteinases, their production by monocytes and macrophages and their potential role in hiv-related diseases. J Leukoc Biol 2006;80:1052-1066.

2 Hijova E: Matrix metalloproteinases: Their biological functions and clinical implications. Bratisl Lek Listy 2005;106:127-132.

3 Vu TH, Shipley JM, Bergers G, Berger JE, Helms JA, Hanahan D, Shapiro SD, Senior RM, Werb Z: Mmp-9/ gelatinase $\mathrm{b}$ is a key regulator of growth plate angiogenesis and apoptosis of hypertrophic chondrocytes. Cell 1998;93:411-422.

4 Merdad A, Karim S, Schulten HJ, Dallol A, Buhmeida A, Al-Thubaity F, Gari MA, Chaudhary AG, Abuzenadah AM, Al-Qahtani MH: Expression of matrix metalloproteinases ( $\mathrm{mmps}$ ) in primary human breast cancer: Mmp-9 as a potential biomarker for cancer invasion and metastasis. Anticancer Res 2014;34:1355-1366.

5 Derosa G, Ferrari I, D'Angelo A, Tinelli C, Salvadeo SA, Ciccarelli L, Piccinni MN, Gravina A, Ramondetti F, Maffioli P, Cicero AF: Matrix metalloproteinase-2 and -9 levels in obese patients. Endothelium 2008;15:219-224.

6 Unal R, Yao-Borengasser A, Varma V, Rasouli N, Labbate C, Kern PA, Ranganathan G: Matrix metalloproteinase- 9 is increased in obese subjects and decreases in response to pioglitazone. J Clin Endocrinol Metab 2010;95:2993-3001.

7 Surmi BK, Hasty AH: Macrophage infiltration into adipose tissue: Initiation, propagation and remodeling. Future Lipidol 2008;3:545-556.

8 Kinne RW, Brauer R, Stuhlmuller B, Palombo-Kinne E, Burmester GR: Macrophages in rheumatoid arthritis. Arthritis Res 2000;2:189-202.

9 Kong YZ, Yu X, Tang JJ, Ouyang X, Huang XR, Fingerle-Rowson G, Bacher M, Scher LA, Bucala R, Lan HY: Macrophage migration inhibitory factor induces mmp-9 expression: Implications for destabilization of human atherosclerotic plaques. Atherosclerosis 2005;178:207-215.

10 Zhou J, Zhang J, Chao J: Porphyromonas gingivalis promotes monocyte migration by activating mmp-9. J Periodontal Res 2012;47:236-242.

11 Rosenberg GA: Matrix metalloproteinases in neuroinflammation. Glia 2002;39:279-291.

12 Gong Y, Hart E, Shchurin A, Hoover-Plow J: Inflammatory macrophage migration requires mmp-9 activation by plasminogen in mice. J Clin Invest 2008;118:3012-3024.

13 Kim MK, Reaven GM, Chen YD, Kim E, Kim SH: Hyperinsulinemia in individuals with obesity: Role of insulin clearance. Obesity 2015;23:2430-2434.

14 Carpentier AC: Hypertriglyceridemia associated with abdominal obesity: Getting contributing factors into perspective. Arterioscler Thromb Vasc Biol 2015;35:2076-2078.

15 Arner P, Ryden M: Fatty acids, obesity and insulin resistance. Obesity facts 2015;8:147-155.

16 Boden G: Obesity and free fatty acids. Endocrinol Metab Clin North Am 2008;37:635-646, viii-ix.

17 Lee JY, Sohn KH, Rhee SH, Hwang D: Saturated fatty acids, but not unsaturated fatty acids, induce the expression of cyclooxygenase-2 mediated through toll-like receptor 4. J Biol Chem 2001;276:1668316689.

18 Weigert C, Brodbeck K, Staiger H, Kausch C, Machicao F, Haring HU, Schleicher ED: Palmitate, but not unsaturated fatty acids, induces the expression of interleukin- 6 in human myotubes through proteasomedependent activation of nuclear factor-kappab. J Biol Chem 2004;279:23942-23952.

19 Haversen L, Danielsson KN, Fogelstrand L, Wiklund O: Induction of proinflammatory cytokines by longchain saturated fatty acids in human macrophages. Atherosclerosis 2009;202:382-393.

20 Schwartz EA, Zhang WY, Karnik SK, Borwege S, Anand VR, Laine PS, Su Y, Reaven PD: Nutrient modification of the innate immune response: A novel mechanism by which saturated fatty acids greatly amplify monocyte inflammation. Arterioscler Thromb Vasc Biol 2010;30:802-808.

21 Jialal I, Kaur H, Devaraj S: Toll-like receptor status in obesity and metabolic syndrome: A translational perspective. J Clin Endocrinol Metab 2014;99:39-48.

22 Shi H, Kokoeva MV, Inouye K, Tzameli I, Yin H, Flier JS: Tlr4 links innate immunity and fatty acid-induced insulin resistance. J Clin Invest 2006;116:3015-3025.

23 Caesar R, Tremaroli V, Kovatcheva-Datchary P, Cani PD, Backhed F: Crosstalk between gut microbiota and dietary lipids aggravates wat inflammation through tlr signaling. Cell Metab 2015;22:658-668.

24 Takeda K, Akira S: Tlr signaling pathways. Semin Immunol 2004;16:3-9. 


\section{Cellular Physiology Cell Physiol Biochem 2016;39:889-900 \begin{tabular}{l|l|l|}
\hline DOI: 10.1159/000447798 & $\begin{array}{l}\text { C) } 2016 \text { The Author(s). Published by S. Karger AG, Basel } \\
\text { www.karger.com/cpb }\end{array}$ \\
\hline
\end{tabular} \\ Sindhu et al.: Palmitate Induces MMP-9 in Human Monocytic Cells}

25 Staiger H, Staiger K, Stefan N, Wahl HG, Machicao F, Kellerer M, Haring HU: Palmitate-induced interleukin-6 expression in human coronary artery endothelial cells. Diabetes 2004;53:3209-3216.

26 Shihab PK, Al-Roub A, Al-Ghanim M, Al-Mass A, Behbehani K, Ahmad R: Tlr2 and ap-1/nf-kappab are involved in the regulation of mmp-9 elicited by heat killed listeria monocytogenes in human monocytic thp-1 cells. J Inflamm (Lond) 2015;12:32.

27 Ahmad R, El Bassam S, Cordeiro P, Menezes J: Requirement of tlr2-mediated signaling for the induction of il-15 gene expression in human monocytic cells by hsv-1. Blood 2008;112:2360-2368.

28 Ahmad R, Shihab PK, Jasem S, Behbehani K: Fsl-1 induces mmp-9 production through tlr-2 and nf-kappab / ap-1 signaling pathways in monocytic thp-1 cells. Cell Physiol Biochem 2014;34:929-942.

29 Bunn RC, Cockrell GE, Ou Y, Thrailkill KM, Lumpkin CK, Jr., Fowlkes JL: Palmitate and insulin synergistically induce il-6 expression in human monocytes. Cardiovasc Diabetol 2010;9:73.

30 Rhee JW, Lee KW, Kim D, Lee Y, Jeon OH, Kwon HJ, Kim DS: Nf-kappab-dependent regulation of matrix metalloproteinase-9 gene expression by lipopolysaccharide in a macrophage cell line raw 264.7. J Biochem Mol Biol 2007;40:88-94.

31 Vaday GG, Hershkoviz R, Rahat MA, Lahat N, Cahalon L, Lider O: Fibronectin-bound tnf-alpha stimulates monocyte matrix metalloproteinase-9 expression and regulates chemotaxis. J Leukoc Biol 2000;68:737747.

32 Lin CC, Kuo CT, Cheng CY, Wu CY, Lee CW, Hsieh HL, Lee IT, Yang CM: Il-1 beta promotes a549 cell migration via mapks/ap-1- and nf-kappab-dependent matrix metalloproteinase-9 expression. Cell Signal 2009;21:1652-1662.

33 Lee DK, Park EJ, Kim EK, Jin J, Kim JS, Shin IJ, Kim BY, Lee H, Kim DE: Atorvastatin and simvastatin, but not pravastatin, up-regulate lps-induced mmp-9 expression in macrophages by regulating phosphorylation of erk and creb. Cell Physiol Biochem 2012;30:499-511.

34 Fischoeder A, Meyborg H, Stibenz D, Fleck E, Graf K, Stawowy P: Insulin augments matrix metalloproteinase-9 expression in monocytes. Cardiovasc Res 2007;73:841-848.

35 Yang CQ, Li W, Li SQ Li J, Li YW, Kong SX, Liu RM, Wang SM, Lv WM: Mcp-1 stimulates mmp-9 expression via erk $1 / 2$ and p38 mapk signaling pathways in human aortic smooth muscle cells. Cell Physiol Biochem 2014;34:266-276.

36 Yeop Han C, Kargi AY, Omer M, Chan CK, Wabitsch M, O'Brien KD, Wight TN, Chait A: Differential effect of saturated and unsaturated free fatty acids on the generation of monocyte adhesion and chemotactic factors by adipocytes: Dissociation of adipocyte hypertrophy from inflammation. Diabetes 2010;59:386-396.

37 Tsukumo DM, Carvalho-Filho MA, Carvalheira JB, Prada PO, Hirabara SM, Schenka AA, Araujo EP, Vassallo J, Curi R, Velloso LA, Saad MJ: Loss-of-function mutation in toll-like receptor 4 prevents diet-induced obesity and insulin resistance. Diabetes 2007;56:1986-1998.

38 Schilling JD, Machkovech HM, He L, Sidhu R, Fujiwara H, Weber K, Ory DS, Schaffer JE: Palmitate and lipopolysaccharide trigger synergistic ceramide production in primary macrophages. J Biol Chem 2013;288:2923-2932.

39 Alvarez-Garcia O, Rogers NH, Smith RG, Lotz MK: Palmitate has proapoptotic and proinflammatory effects on articular cartilage and synergizes with interleukin-1. Arthritis Rheumatol 2014;66:1779-1788.

40 Senn JJ: Toll-like receptor-2 is essential for the development of palmitate-induced insulin resistance in myotubes. J Biol Chem 2006;281:26865-26875.

41 Lee JY, Ye J, Gao Z, Youn HS, Lee WH, Zhao L, Sizemore N, Hwang DH: Reciprocal modulation of toll-like receptor-4 signaling pathways involving myd88 and phosphatidylinositol 3-kinase/akt by saturated and polyunsaturated fatty acids. J Biol Chem 2003;278:37041-37051.

42 Joshi-Barve S, Barve SS, Amancherla K, Gobejishvili L, Hill D, Cave M, Hote P, McClain CJ: Palmitic acid induces production of proinflammatory cytokine interleukin-8 from hepatocytes. Hepatology 2007;46:823830. 